\title{
Prime time advertisements: Repetition priming from faces seen on subject recruitment posters
}

\author{
VICKI BRUCE and DEREK CARSON \\ University of Stirling, Stirling, Scotland \\ and \\ A. MIKE BURTON and STEVE KELLY \\ University of Glasgow, Glasgow, Scotland
}

\begin{abstract}
Repetition priming is defined as a gain in item recognition after previous exposure. Repetition priming of face recognition has been shown to last for several months, despite contamination by every'day exposure to both experimental and control faces in the interval. Here we show that gains in face recognition in the laboratory are found from faces initially seen in a rather different contexton subject recruitment posters, even when the advertisements make no specific mention of experiments involving face recognition. The priming was greatest when identical pictures were shown in the posters and in the test phase, although different views of faces did give significant priming in one study. Follow-up studies revealed poor explicit memory for the faces shown on the posters. The results of these experiments are used to develop a model in which repetition priming reflects the process of updating representations of familiar faces.
\end{abstract}

Repetition priming is the gain in item recognition after earlier exposure to the item and is of considerable contemporary interest, because of the dissociations that occur between repetition priming and episodic memory (see, e.g., Roediger \& McDermott, 1993, for a review). ${ }^{1}$ Most research on priming has used verbal materials and a variety of experimental means for tapping implicit memory, including word stem or word fragment completion (see, e.g., Graf, Squire, \& Mandler, 1984; Roediger, Weldon, Stadler, $\&$ Riegler, 1992) and latency of lexical decisions (see, e.g., Duchek \& Neely, 1989). Repetition priming has also been demonstrated for a range of other materials, including pictures of objects (see, e.g., Biederman \& Cooper, 1991) and faces (see, e.g., Bruce \& Valentine, 1985; Ellis, Young, Flude, \& Hay, 1987).

In experiments on the repetition priming of faces, the paradigm most often used involves looking for gains in the

This research was supported by a grant from the U.K. Economic and Social Research Council (R000234574). We thank all subjects in these studies as well as the staff at the University of Paisley and the Open University, who allowed us to recruit subjects from among their students. Some of these experiments were described in papers presented to the Experimental Psychology Society (1995) and the British Psychological Society (1996), and titles and abstracts of these talks have been published in these societies' Proceedings. We thank Michael Masson, R. L. Greene, and other reviewers of this paper who have helped to shape the final version. Correspondence concerning this article should be addressed to V. Bruce, Department of Psychology, University of Stirling, Stirling, Scatland, FK9 4LA, UK (e-mail: vicki.bruce@stir.ac.uk).

-Accepted by previous editor, Geoffrey R. Loftus times taken to make a two-choice decision in the test phase of an experiment, as a function of earlier exposure to a subset of the test items. Typically, subjects in the test phase of an experiment are asked to decide, as quickly but as accurately as possible, whether faces are familiar (= famous) or unfamiliar. The average time taken to make these decisions for a set of faces that were seen earlier ( primed) is compared with the time taken for items that had not previously been presented within the experimental materials (unprimed). The test phase in such experiments usually does not involve the repetition of responses from the earlier exposure. Often subjects are asked to name faces in the exposure phase and then to make speeded familiarity judgments at test.

With this type of methodology, it has been shown on a number of occasions that the repetition priming of faces is obtained from earlier exposure to the same pictures of familiar celebrities (Bruce \& Valentine, 1985; Ellis, Young, \& Flude, 1990; Ellis et al., 1987; for reviews, see Bruce, Burton, Carson, Hanna, \& Mason, 1994; Ellis, 1992; Young, 1994), and that it is obtained, although reduced in magnitude, after exposure to different pictures of the celebrities (Bruce \& Valentine, 1985; Ellis et al., 1987). Priming of face familiarity decision is not obtained from earlier exposure to the names of the celebrities (Bruce \& Valentine, 1985; Ellis et al., 1987), nor is face recognition primed by earlier exposure to pictures of the headless bodies of the people (Ellis et al., 1987). Repetition priming of faces is highly sensitive to the format in which pictured exemplars appear (Bruce et al., 1994), with reductions in the amount of priming if the photographs of faces are followed by high quality line drawings derived from the same portraits or vice versa. 
In experiments that used identical pictures of faces from prime to test phases, it has been shown that repetition priming of faces is very long-lasting. Flude, Young, and Ellis (1991; see also Flude, 1993) found repetition priming several months after initial exposure to celebrities' faces, as did Maylor (1998), who used a naming task rather than a face familiarity decision task. Flude (1993) also found no reduction in the amount of priming between delays of $5 \mathrm{~min}$ and of 4 weeks, whether testing with the same or different views from those seen at presentation. A similar result was found by Bruce et al. (1994), who showed that there was no reduction in priming at 1 week, as compared with that shown after a 10-min delay, and that the length of delay did not reduce the magnitude of the effect of changing format from a line drawing to a photograph. The longevity of the repetition priming effect for celebrities' faces is surprising, given that it is likely that both primed and unprimed items might be seen in a nonexperimental context in the interval, thus diluting any differential effect of the priming episode itself. Flude et al. examined this by comparing the amount of priming obtained over a 3month period from faces likely to be seen infrequently during that time (low current exposure in the media-e.g., Winston Churchill) and from those likely to be seen more frequently (high current exposure in the media-e.g., Bill Clinton). More priming was found for the low current exposure faces, consistent with this proposal that intervening exposure should reduce priming. Nevertheless, significant priming was found even for high-exposure faces, where both primed and unprimed items were likely to be encountered beyond the experimental context during the 3-month interval from the prime phase to the test phase.

This raises the possibility that contextual factors influence priming. If priming arises because of the repetition of a stimulus in its experimental context, this would create some immunity to the effects of extraexperimental encounters with test items. At a theoretical level, the possibility that priming may be contextually moderated is relevant not only to the specific area of face recognition, but also to the more general debate between episodic accounts of priming and structural accounts. According to episodic accounts of priming (see, e.g., Jacoby, 1983; Roediger \& Blaxton, 1987), priming should be stronger the more there is a repetition of stimulus and response processing between the prime and test episodes. The episodic account can quite easily explain any factors - such as the effect of a change in exemplar - that affect direct tests of episodic memory and repetition priming similarly. Where dissociations are observed between factors that affect direct tests of episodic memory and those that affect repetition priming, these are generally explained in terms of the relative contribution of such factors to control processes or retrieval strategies that affect conscious recollection, as opposed to perceptual and/or automatic processes that affect priming. If repetition priming were reduced or eliminated after a change in context, an episodic model of priming could explain this in a straightforward manner.
By contrast, structural models of repetition priming (see, e.g., Biederman \& Cooper, 1991; Burton, Bruce, \& Johnston, 1990; Warren \& Morton, 1982) assert that repetition priming arises as a result of changes within the representational system that is used for the recognition and identification of words, objects, or faces. Such models can account for the standard effects reported above. For example, Bruce et al. (1994) discuss how a structural model could accommodate the observed reduction of face priming after a change in pictured exemplar. More recently, Burton, Bruce, and Hancock (1998) have simulated this changed exemplar effect with an interactive activation model (developed from Burton et al., 1990) in which repetition priming reflects the strengthening of connections between representational units within the person recognition system. As currently formulated, however, there is no obvious way for structural accounts to explain contextual influences on repetition priming. To the extent that priming is diminished or abolished after contextual change, episodic models appear to be favored over structural ones.

To date, there have been relatively few studies that examine contextual influences on the priming of nonverbal materials, and their results are inconsistent. A number of researchers have reported that repetition priming of words is reduced or eliminated if there is a change in context between the study (prime) and the test phases, particularly in cases in which the contextual change is accompanied by a change in the perceived meaning or sense of the word (Bainbridge, Lewandowsky, \& Kirsner, 1993; Oliphant, 1983; but see Valentine, Moore, Flude, Young, \& Ellis, 1993, for an important exception). In contrast, however, a recent study by Dean and Young (1997) found that the priming of both words and novel object shapes was unaffected by changes in interpretation and/or context, results that favored at least some versions of the structural accounts of repetition priming. There are no published studies in which context has been manipulated in studies of face priming, although Flude (1993) did conduct studies in which faces were primed in an undergraduate laboratory class and tested in a different experimental room, but the results across three separate experiments were inconsistent.

There are a number of different ways in which the context in which faces are encountered could be defined and manipulated. The term context has been used to cover a huge range of factors-including environment, interpretation, and mood-provoking Smith, Glenberg, and Bjork (1978) to describe context as "a kind of conceptual garbage can that denotes a great variety of intrinsic and extrinsic characteristics of the presentation and test of an item (p. 342)." Davies (1988) reviews the effects of different kinds of contextual change on memory for previously unfamiliar faces. Previous studies have shown significant effects of reinstating as compared with changing the face pairs within which target faces were presented (Winograd \& RiversBulkeley, 1977), reinstating descriptive phrases accompanying target faces (Watkins, Ho, \& Tulving, 1976), and reinstating the clothing worn by targets (see, e.g., Thomson, 
Robertson, \& Vogt, 1982) in recognition memory. Consistent effects have also been found as a result of maintaining or changing the background context upon which faces were placed. For example, Beales and Parkin (1984) found that memory performance was $91 \%$ when faces were paired with their original background scenes, but only $37 \%$ when background was changed. Memon and Bruce (1983) also found that recognition accuracy in an incidental memory task was higher when faces were tested against the same pictured backgrounds on which they had been initially studied. Wagstaff (1982) reported that police cadets were better able to recognize an instructor several weeks after a lecture when retested in the same room, and Davies and Milne (1985) found that Photofits produced in a face recall task were rated better likenesses when they had been constructed in the room in which the person was originally encountered. Reviewing this literature, Davies (1988) suggests that environmental cues, such as places and background scenes where faces are depicted or encountered, yield the strongest contextual effects in the memory for faces. Our aim was to see whether priming effects were moderated by being tied to specific experimental episodes or encounters; thus, we attempted to the kinds of contextual cues previously found important in episodic memory for faces. To do this, we manipulated a range of environmental cues associated with the presentation of the prime faces.

We compared priming obtained from faces seen on advertising posters with that obtained from a different set of faces presented within the laboratory session itself, against unprimed control items. Those faces seen on the posters were initially studied in a different setting with a range of environmental cues that were different from those of the experimental room, in a different format (on paper rather than on a computer screen), and without the experimenter present, as compared with those faces primed within the laboratory setting itself. However, whether such manipulations alter the functional aspects of context for identification of familiar faces may be debated, and we discuss possible limitations later in the paper.

Before proceeding with the experiments proper, various pilot procedures were conducted in order to select suitable groups of faces for allocation to the three different conditions, since as in most of the experiments reported, it was not possible to use a counterbalanced design.

\section{GENERAL METHOD}

\section{Materials}

Three matched groups of eight famous faces were selected on the basis of the pilot work described in Appendix A. The faces were digitized from video, cut out from their backgrounds, and pasted onto uniform dark backgrounds. Additional famous and unfamiliar faces were collected from similar sources and were prepared in the same way.

\section{Design and Procedure}

In all of the experiments reported, we compared repetition priming obtained from one group of faces initially encountered on recruitment posters (primed by poster; abbreviated poster) with the priming obtained from a second group seen for the first time in the laboratory session about $10 \mathrm{~min}$ before the test phase (primed in lab; abbreviated $l a b$ ). In the test phase of the experiment, both primed groups of faces were presented intermixed with a third group of unprimed famous faces (unprimed) seen for the first time in the test phase, a set of unfamiliar faces, and additional familiar filler items (to reduce the proportion of primed faces appearing in the test series). We were interested in the relative speed and accuracy of familiarity decisions for the three groups of famous faces (poster, lab, and unprimed) at test. Primed items were previously presented in conditions that sometimes required that the faces be named or that sometimes exposed them without any direction to name or identify the faces at all, depending on the experiment. The test phase never involved the repetition of responses from the earlier exposure. The hypotheses tested do not relate to the unfamiliar faces, which were present merely to create the task demands of the familiarity decision, and so we do not analyze data for the unfamiliar faces, although the speed and accuracy of rejecting unfamiliar faces in each experiment are reported.

Once faces have been put onto a subject recruitment poster, it is impossible to withdraw them and reallocate these faces to another condition of the experiment, and so, in some of our experiments, we were unable to rotate items around conditions. However, in Experiments 2 and 4, we were able to make use of several successive weeks of visiting summer school students, and, for these experiments, reallocation of items to conditions was possible.

There are many differences between the conditions of exposure of the faces on the posters and in the laboratory. The poster faces may have been viewed for variable and/or repeated periods of time, whereas the lab faces are seen once for 2 sec each in the prime phase. This means that we must be cautious about comparing the absolute size of the priming obtained from the lab and poster faces. However, there is little evidence that repeated or extended exposure to items influences repetition priming at all (see Roediger \& McDermott's 1993 review), whereas it is clear that increase in exposure duration and/or frequency does affect explicit memory for the items. For example, Jacoby and Dallas (1981) found no difference between presentation durations of 1 and $2 \mathrm{sec}$ on primed word identification, but this manipulation did increase recognition memory for the words. Greene (1986) had subjects repeat words aloud for either $2 \mathrm{sec}$ or $10 \mathrm{sec}$ and found that this repetition increased accuracy on a direct test of cued recall but had no effect on priming, as measured by word stem completion. Weldon, Roediger, Beitel, and Johnston (1995) found that repetition of words or pictures did not affect performance on implicit memory tests of fragment completion but did improve performance on a direct test of episodic memory. In later experiments, we assess episodic memory for the poster faces in two different ways. In one test, subjects attempt to remember which faces appeared on the poster and which were shown to them earlier in the lab; we compare the recognition accuracy for the two groups of items. We also tested episodic memory for the poster faces by examining whether exposure to the faces on the posters would lead to difficulties in rejecting these faces as new items in a test of recognition memory for faces shown in the lab. Repeated or extended encounters with the faces on the posters, as compared with those seen in the laboratory, should tend to increase memory for these items in such episodic recognition tests, although, as we see, memory for the poster faces as tested with either method was very poor.

\section{EXPERIMENT 1}

Experiment 1 was a small-scale preliminary study, conducted to explore whether priming from posters was observable at all. Its results motivated the series of further experiments that we report.

We compared priming from one set of items seen on an advertising poster with priming from another set seen in 
the lab immediately prior to the test phase of our experiment. One problem that might reduce the likelihood of observing priming from the poster faces is that face priming in the lab only occurs from faces that subjects can recognize (Brunas-Wagstaff, Young, \& Ellis, 1992), and we have no way of knowing whether subjects are able to recognize the faces shown in the poster. In our first experiment, therefore, we tried to ensure from the wording on the poster that only subjects familiar with the faces shown there would be recruited. ${ }^{2}$

\section{Method}

Subjects. Twelve students at the University of Stirling were tested. None had participated in any previous experiments on familiar face recognition in our laboratory.

Materials. A poster was constructed which showed the eight faces allocated to Group 1 (see Appendix B). Faces were painted onto a plain black background, and, on the poster, each face was approximately $5 \mathrm{~cm}$ in height. The poster was worded as follows:

Can you name these famous faces?

[followed by pictures of the eight faces]

If you can, we need you to take part in some psychology experiments. So phone Derek on 7659 or come along to $3 \mathrm{~B} 114$ to arrange a suitable time. Hurry, places are limited!

All other faces were displayed on a Macintosh Centris, using the laboratory package Superlab. Each face was shown in an image approximately $5 \mathrm{~cm}$ square with 8-bit gray-scale resolution.

Procedure. The posters invited subjects to phone or call at the laboratory to make an appointment for testing. Typically, subjects phoned in and were tested within a few days of the poster having appeared on campus. In the test session itself, subjects were initially shown a set of 12 faces (the 8 faces from Group 2 plus four fillers) and instructed to name these. Responses were counted as correct if the faces were correctly named or a detailed occupational description produced.

After a delay of about $10 \mathrm{~min}$ filled with an unrelated object recognition experiment, subjects proceeded to the test phase of the experiment, in which they were asked to make speeded familiarity decisions to 58 faces $(28$ unfamiliar plus the 24 critical familiar faces-Group 1 previously seen on the poster [poster], Group 2 previously seen in the lab [lab], and Group 3 not previously seen [unprimed] - plus 6 additional famous faces to increase the proportion of unprimed items).

\section{Results}

In this and all subsequent experiments, responses that were made faster than $300 \mathrm{msec}$ or slower than $2,000 \mathrm{msec}$ were excluded from the analysis and counted among the error rates. Exclusions on these grounds accounted for fewer than $1 \%$ of all responses to familiar faces, although a much greater number of slow responses were made to unfamiliar faces, inflating the reported error rates to these items. In addition, analysis of response times (RTs) to faces primed in the lab were based only upon faces that had been identified correctly in the prime phase. This removes any possible bias that is due to the self-selection of subjects able to name the poster faces. ${ }^{3}$ Exclusions on this basis were very rare (all items for these experiments were carefully selected to be highly familiar to the target population; see Appendix A)

The mean times to make familiarity decisions to the three sets of items in the test phase were as follows: Group 1 (poster), $622 \mathrm{msec}(S D=88 \mathrm{msec}$ ); Group 2 (lab), $611 \mathrm{msec}$ $(S D=85 \mathrm{msec}$ ); and Group 3 (unprimed), $737 \mathrm{msec}(S D=$ $167 \mathrm{msec})$. Error rates were uniform and below $3.5 \%$. RTs to unfamiliar faces averaged $915 \mathrm{msec}(S D=195 \mathrm{msec})$, with a $15.3 \%$ error rate $(11 \%$ genuine errors, the remainder exclusions). An analysis of variance (ANOVA) on the recognition latencies to familiar faces showed that there was a main effect of prime $[F(2,22)=13.39, p<.001$, by subjects; $F(2,21)=15.55, p<.001$, by items], with faces in the lab and poster conditions being responded to more quickly than the unprimed faces $(p<.01$, by subjects and by items). There was no significant difference between the two primed conditions ( $p>.1$, by subjects and by items). However, the power of this comparison within this experiment was very low $(0.22$, assuming a medium effect size, as defined by Cohen, 1977). Later experiments in this series compared priming from posters and lab in designs of much higher power.

\section{Discussion}

Experiment 1 showed that, when subjects are invited to name the faces shown on a poster in order to volunteer for experiments on face recognition, the same amount of priming is shown for these items as for ones shown immediately before the test phase, in the laboratory on the same equipment. In our next experiment, we examined priming from a poster that made no mention of experiments on face processing at all.

\section{EXPERIMENT 2}

In this experiment, we placed faces on an advertising poster that recruited subjects for a quite different set of experiments on the design of new UK coins (cf. Bruce \& Hellawell, 1988). We were able to exploit the presence of a visiting university summer school, where different students attended each week, to run a fully counterbalanced design, in which a different set of faces was put out on the recruiting poster for each week's testing. The sample size of this experiment was also enlarged to increase the power of the design.

\section{Method}

Subjects. The subjects were thirty-six students attending 3 successive weeks of an Open University summer school at the University of Stirling during the summer of 1994.

Materials. Each of the three groups of faces (Appendix B) was in turn presented on a different poster, with the posters changed with each new intake of students to the summer school.

Each poster presented eight faces with the following wording (adapted slightly between posters in order to cater to the range of occupational groups represented).

Who helps shape the nation's coins-is it politicians? 


\author{
[pictures of politicians] \\ royalty? \\ [pictures of royalty] \\ entertainers? \\ [pictures of entertainers]. \\ It could be YOU! Psychology at Stirling University has a contract from \\ the Royal Mint to evaluate new 50p and $£ 2$ coins. If YOU would like to \\ take part in our trials, or any of the experiments we have on offer then \\ come along to room 4:9 in ASH NOW. You will receive payment in cash, \\ and get a full explanation of the rationale behind experiments.
}

Design and Procedure. Thirty-six subjects were recruited through the posters. Posters were displayed on the Sunday of each week, and subjects were tested 2-4 days later. During the rather long experimental sessions on coin sorting, subjects were asked if they would be willing to participate in an experiment on face and object recognition.

The procedure was then the same as that for Experiment 1. Twelve subjects were tested in each of the counterbalancing conditions obtained by ensuring that each group of items appeared in each of the poster, lab, and unprimed conditions.

\section{Results}

Faces that had been previously seen incidentally on posters were responded to at test with a mean of $773 \mathrm{msec}$ $(S D=144 \mathrm{msec})$, compared with $678 \mathrm{msec}(S D=112 \mathrm{msec})$ for faces seen and named initially in the lab and $822 \mathrm{msec}$ $(S D=190 \mathrm{msec})$ for unprimed faces. Error rates were uniform and below $6.5 \%$. The time to respond correctly to unfamiliar faces averaged $996 \mathrm{msec}(S D=269 \mathrm{msec})$, with an error rate of $10.3 \%$ ( $6 \%$ were genuine errors, the remainder exclusions). An ANOVA on the recognition latencies to familiar faces showed a main effect of prime condition $[F(2,70)=35.3, p<.001 ; F(2,46)=22.0$, $p<.001$ by items], with both poster and lab conditions giving priming, compared with unprimed faces (for the comparison between poster and unprimed faces, $t=2.84$ by subjects, $t=2.4$ by items; both $p$ s $<.01$ ). The faces in the lab conditions were, however, responded to more quickly than those previously shown on the poster $(t=$ 5.43 by subjects; $t=4.12$ by items; $p<.01$ ).

\section{Discussion}

Despite the fact that we do not know whether the subjects in this experiment looked at any or all of the faces on the poster, and we can assume that they probably did not attempt to name them, significant priming was observed from faces that had been encountered in this way, although this was substantially less than the priming we found from faces seen and named in the laboratory. In the next experiment, we examined whether such priming would also be found if the faces on the poster showed different exemplars of the people from those seen in the test phase. Experiment 3 also included within a single experiment a direct comparison of posters that did or did not invite subjects to name the faces on the poster before volunteering. This was achieved by testing subjects at two new universities, where students had not seen any previous posters. As in all other experiments in this series, the task at test was a speeded familiarity decision task made to a series of famous and unfamiliar faces.

\section{EXPERIMENT 3}

\section{Method}

Subjects. The subjects were 24 students at the University of Glasgow and 24 students at the University of Paisley, recruited during the first part of 1995 .

Materials. Two new posters were constructed. The first (used in Glasgow) was similar to that in Experiment 1, inviting subjects to name the faces shown. The second poster (used in Paisley) was worded as follows:

Who are the people that volunteer for our psychology experiments-is it politicians?

[pictures of politicians]

royalty

[picture of royalty], etc.

No, but it could be you ... etc.

Both versions of the poster showed the eight celebrities of Group 1 (cf. Experiment 1). However, half of these people were shown in pictures different from those used in the test phase, and half were shown in identical pictures. Similarly, in the group of faces primed in the lab, half were primed in different pictures and half in same pictures. The two different pictures of each celebrity showed some variation in both viewpoint and expression, although it was not possible to control this carefully, as we were limited by available pictures. All pictures used in the test phase were the same as those used in Experiments 1 and 2, and the allocation of faces to same and different picture conditions was done so that the four members of each subgroup had similar mean familiarity decision times when unprimed in our pilot work (Appendix A). The mean decision times to the subgroups of four faces in Experiment 3 were $735 \mathrm{msec}$ (posterdifferent exemplar), $732 \mathrm{msec}$ (lab-different exemplar), $736 \mathrm{msec}$ (poster-same exemplar), and $730 \mathrm{msec}$ (lab-same exemplar).

Design and Procedure. We compared the effects of the wording on the posters between subjects, although this variable was also confounded with possible differences in the student populations tested at the two universities and other incidental differences in the experimental set-up. The conditions of place of priming (lab vs. poster) and exemplar (same vs. different) were within-subjects factors, but it was not possible to rotate items around the different conditions of this experiment.

As there were only four items in each cell and counterbalancing was not possible, the items analysis for this experiment lacks power and is not reported.

\section{Results}

The mean RTs and error rates in each condition of interest are shown in Table 1. An initial by-subjects ANOVA examined overall priming (collapsed over same and different views) from the poster and lab conditions, as compared with unprimed faces, at each university/poster type. This revealed only a significant main effect of priming $[F(2,92)=17.3, p<.001]$, with overall means of $647 \mathrm{msec}$ for faces primed in the lab, $669 \mathrm{msec}$ for faces primed on the poster, and $719 \mathrm{msec}$ for unprimed faces. There was no effect of university/poster type or interaction between university and priming $(F \mathrm{~s}<1.0)$. (An equivalent items analysis was not appropriate here, as there was no sensi- 
Table 1

Mean Reaction Times (RTs, in Milliseconds) and

Percentage of Errors, With Standard Deviations (SDs), in the Test Phase in Each of the Conditions in Experiment 3

\begin{tabular}{|c|c|c|c|c|c|c|c|c|}
\hline \multirow[b]{3}{*}{ Prime Type } & \multicolumn{8}{|c|}{ Poster Type } \\
\hline & \multicolumn{4}{|c|}{$\begin{array}{c}\text { Name faces } \\
\text { (University of Glasgow) }\end{array}$} & \multicolumn{4}{|c|}{$\begin{array}{c}\text { Incidental } \\
\text { (University of Paisley) }\end{array}$} \\
\hline & RT & $S D$ & $\%$ Errors & $S D$ & RT & $S D$ & $\%$ Errors & $S D$ \\
\hline \multicolumn{9}{|l|}{ Poster } \\
\hline Same exemplar & 638 & 83 & 0 & 0 & 644 & 115 & 4 & 9 \\
\hline Different exemplar & 726 & 147 & 0 & 0 & 664 & 135 & 2 & 7 \\
\hline \multicolumn{9}{|l|}{$\mathrm{Lab}$} \\
\hline Same exemplar & 644 & 143 & 0 & 0 & 624 & 134 & 1 & 5 \\
\hline Different exemplar & 666 & 106 & 1 & 5 & 658 & 156 & 4 & 12 \\
\hline Unprimed & 741 & 112 & 6 & 9 & 697 & 135 & 9 & 11 \\
\hline Unfamiliar & 970 & 267 & 12 & 9 & 879 & 222 & 10 & 10 \\
\hline
\end{tabular}

ble way of pooling the same-exemplar and differentexemplar items.)

An additional by-subjects analysis was conducted on the amount of priming observed in each condition, obtained by extracting the times to make familiarity decisions to primed groups from times for unprimed items. An ANOVA with factors of type of poster, place of priming, and exemplar type (same or different exemplar at test) showed significantly greater priming for same than for different exemplars $[F(1,46)=17.45, p<.001]$ and a trend for greater priming in the lab condition than in the poster condition $[F(1,46)=3.11, p=.085]$ but no other significant effects or interactions (all other $p s>.15$ ). Thus, the direct comparison of the two types of poster showed no statistically significant reduction in priming when faces were presented incidentally on the posters, compared with posters that invited the naming of the faces. Figure 1 shows the amount of priming in each condition of Experiment 3, collapsed across the two different poster types/universities. Planned comparisons showed a significant difference between primed and unprimed items for all conditions except posters showing different views.

\section{Discussion}

Experiment 3 made a direct comparison between the different conditions in Experiments 1 and 2, in which posters either invited or did not invite explicit naming of the faces. No significant reduction in the priming effect was found when the faces were presented incidentally, although Table 1 shows that the trend was for somewhat less priming under this condition. Changing the exemplar between prime and test phases had similar effects for both poster and lab faces, and the effect of changing the exemplar on the poster faces reduced the priming from these items to a level that was not significant with the sample size tested. One aim of Experiment 4 was to replicate the effect of changing view with a larger sample size and with items rotated between same and different exemplar conditions.

Thus, in three separate experiments, we have shown that faces seen on recruitment posters will prime faces later seen in the laboratory, to an extent that is comparable with (though somewhat less than) the priming obtained from items seen in the same laboratory context. This shows clearly, and for the first time, that priming of face recognition does not require the reinstatement of the environmental context associated with the priming experiment itself.

Is it possible that the effects that have been revealed in the priming experiments to date rely on explicit episodic memory of the faces? This seems unlikely, given converging evidence from a number of studies that have found little evidence for episodic influences on face priming. The fact that repetition priming of face recognition is domain-specific is important here (faces prime face familiarity decisions, but names do not; see, e.g., Bruce \& Valentine, 1985; Ellis et al., 1987). Moreover, Ellis et al. (1990)

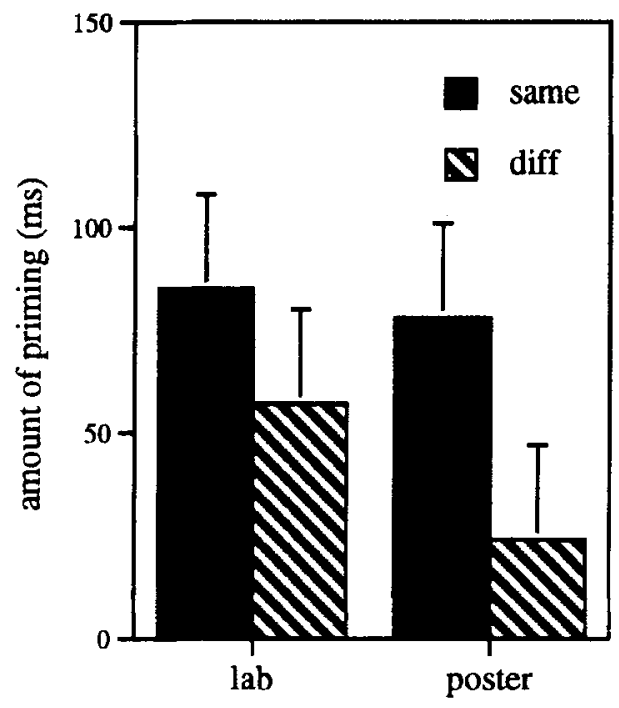

place where prime faces appeared

Figure 1. Amount of priming (mean of unprimed-primed response times, in milliseconds) from same and different exemplars first seen on the poster or in the lab in Experiment 3. Error bars show the within-subjects confidence interval (Loftus $\&$ Masson, 1994). 
found that repetition priming of faces was unaffected by a switch in task between prime and test phases, provided that the test phase required that items be identified, yet priming was not found when repeated decisions were made about the sex or expression of faces - tasks that do not engage the identification system-despite the overlap in both items and responses made to them.

Nonetheless, it is of interest to examine the extent to which faces presented under such incidental conditions are remembered when tested using episodic recognition memory. We began to investigate this with further samples of subjects recruited at the Universities of Glasgow and Paisley.

In one study, we investigated whether prior exposure to the poster faces would generate interference, if these were presented as distractors, when recognition memory for the lab faces was probed. Such interference could arise either as a result of explicit memory for the poster faces or from effects of greater perceptual fluency created by priming or both (cf. Johnston, Dark, \& Jacoby, 1985). In Glasgow (where subjects had seen a poster inviting them to name faces), 15 new subjects were shown the Group 2 faces in the lab (as in the priming experiments), but then, at test, asked to remember the faces they had seen in the lab. The test list comprised a random sequence of the poster faces, the lab faces, and the unprimed faces, plus six additional familiar filler items. All poster and lab faces were retested in identical pictures. The subjects were asked to press one button for faces they recognized as having been shown 10 min earlier in the lab and to press another button to all other faces. We examined whether responses to the poster faces were slower than those to completely novel (unprimed) faces. We found no significant difference between the no responses made to these two groups of items (poster faces-mean rejection latency $=815 \mathrm{msec}, S D=$ $182 \mathrm{msec}, 2.5 \%$ errors; Unprimed faces $-801 \mathrm{msec}, S D=$ $209 \mathrm{msec}, 1.7 \%$ errors). Positive responses to the faces seen in the lab were highly accurate $(99.2 \%$ correct, mean recognition latency $=768 \mathrm{msec}$ ). . However, with this small sample of subjects, and high variance in the latency of the no responses, this study lacked power (power for the comparison of no responses was 0.08 , assuming a small effect, or 0.26 for a medium effect at $\alpha=.05$, using Cohen's 1977 definitions). We decided to replicate this study with a larger sample of subjects in Experiment 4.

We also tested episodic memory for the poster faces directly. A further 22 subjects ( 13 from Glasgow and 9 from Paisley) were recruited and, as usual, named Group 2 faces when they entered the laboratory. Ten min later, they were shown the same series of poster, lab, unprimed, and filler familiar faces (with all old items shown in the same pictorial exemplars), but this time they were asked to press one button if they recognized faces from either the lab or the poster and to press another button for completely novel items. The subjects responded correctly to $95 \%$ of the lab faces and made only $5 \%$ false positives to the unprimed faces. They recognized only $51 \%$ of the poster faces as having been seen before. Although we cannot allocate a true chance rate here (since there is only a single false positive rate for both kinds of target), this is an extremely low rate of performance for the recognition of identical pictures of familiar faces (e.g., Bruce, 1982, found hit rates of $96 \%$ to same pictures and $95 \%$ to different pictures of familiar faces, with $8 \%$ false positives, in a standard face recognition experiment). A further 16 subjects were tested in the same way after being recruited with the same posters at Paisley a year later. These gave hit rates of $95 \%$ to the faces seen in the lab, $33 \%$ to those seen on the poster, and a false positive rate of $15 \%$. Thus, each of the tests of episodic memory revealed very poor memory for the famous faces that had previously been presented on the poster.

In our next experiment, we examined interference from primed items in episodic memory within the same experiment that were used to examine repetition priming and also included an additional sample of subjects tested directly on episodic memory for the faces.

\section{EXPERIMENT 4}

This experiment aimed to replicate the effect of changing the exemplar shown on the posters and in the lab in a design in which items served as both same and different exemplars (and where items were rotated between the poster and lab conditions). The effect of a change in exemplar on episodic memory was also examined.

In addition to the factors of place of priming and exemplar type, in this experiment we also manipulated an additional variable - the background color on which the faces appeared at test (which was either the same as or different from that present during priming). The earlier experiments in this series have replicated the effects of changing the picture on repetition priming of faces in both the experimental and the poster context, and have shown (although not significantly in Experiment 3 ) somewhat reduced priming in the nonexperimental context, as compared with that shown in the lab. The local background on which a face is shown can be viewed as either pictorial or as a contextual detail. Studies of context change (cf. Davies, 1988) have tended to show the effects of changes in detailed scenic backgrounds, and most explanations would not predict any effects of merely changing the color of a background, since this should not interact in any way with the coding of a face (cf. Baddeley \& Woodhead, 1982, and see the general discussion later in this paper). However, in studies of repetition priming of faces, Bruce et al. (1994) have shown face priming to be remarkably sensitive to the specific pattern of gray levels used to depict the face, with priming substantially reduced if gray-level images are compressed to black-on-white. It was thus of some interest to see whether sensitivity to gray-level detail extended to the coloration beyond the border of the face itself.

In this experiment, we used the version of the poster that invited subjects to name the faces. Our subject population again comprised students attending an Open University summer school, but, by the time Experiment 4 was conducted, their course texts included a unit on face recog- 
nition that had been authored by one of the Stirling group (Roth \& Bruce, 1995). We thought it possible that students might anticipate opportunities to participate in experiments on face recognition and therefore thought it better to use a poster that played to any such expectations by inviting subjects who were able to name famous faces to participate in further studies.

\section{Method}

Subjects. These were 144 students tested across 5 successive weeks of an Open University summer school held at the University of Stirling in 1995. Sixty-four subjects participated in the priming study, 64 in the test of interference in episodic memory, and 16 in the direct test of episodic memory.

Materials. For this experiment, there were four slightly different posters, each constructed in the same form as that in Experiment $1-$ that is, inviting subjects who were able to name the faces to participate in experiments in return for cash.

Design and Procedure. The background color in which faces appeared at test was manipulated between subjects. The posters showed faces pasted onto a black background, and the faces primed in the lab were also initially seen on black backgrounds. At test, half of the subjects saw faces again on a black background, and half saw them on a light gray background. The other factors (place of primingposter vs. lab) and exemplar type (same vs. changed) were manipulated within subjects. All subjects saw eight faces in the lab, and eight on the poster, and half of these were tested in the same exemplar and half in a different exemplar. Faces from Groups 1 and 2 (Appendix B) were rotated around conditions between equal-sized subsets of subjects. Thus, all primed items appeared in all four primed conditions. Unprimed items remained the same for all subjects (Group 3 faces).

Before each new intake of students arrived each week, a different poster was mounted in the hall of residence where students were staying and where the experiments were conducted. Thirty-two new subjects were tested on each of 4 consecutive weeks. Half of these subjects were tested on the repetition priming experiment, and half were tested on the test of interference in episodic memory. The procedure for the repetition priming experiment was identical to that described for Experiment 1 . In the test phase, the data of interest were the relative primings from the poster faces and the lab faces, as background color and exemplar were varied.

The procedure for the test of interference on episodic memory was similar to that for the priming experiment, except that, in the test phase, no unfamiliar faces were shown, and the subjects' task was to press one button to faces that they recognized as having been shown earlier in the laboratory and the other button to all other faces. We were interested here in comparing the latency and accuracy of rejecting the poster faces and the unprimed faces, again as a function of variations in the background color and exemplar type in the poster faces.

In the 5 th and final week of the summer school, a further sample of 16 students was recruited with the same poster as in Week 4 . When these arrived, they were again shown the lab faces to name and, after a filled delay, asked to participate in a direct test of episodic memory. Here they were shown poster, lab, unprimed, and filler faces and asked to press one button for faces that they had seen either in the lab or on the poster and the other button for completely new faces. Half of these saw the faces on the same background color and half on a different background color from that of the original exposure.

\section{Results}

Repetition priming. The mean correct RTs in each condition of interest are shown in Table 2. An initial ANOVA comparing times in each of the primed and un- primed conditions between groups of subjects for whom background color was maintained or changed showed only a main effect of priming $[F(1,248)=15.7, p<.001]$ but no interaction between this and the color change factor. The main effect of color approached significance $[F(1,62)=$ $3.1, p=.08$ ], reflecting somewhat faster responses overall for subjects tested with the black $(663 \mathrm{msec})$ rather than the gray $(728 \mathrm{msec})$ background. However, as this effect applied equally to unprimed and primed items (and unfamiliar ones - see Table 2), it seems likely that it is due to overall differences in speed of subject groups, rather than being an effect of color. Planned comparisons showed that significant priming was found in all conditions. Figure 2 shows the amount of priming in the main conditions of interest. An ANOVA conducted on the amounts of priming in each condition of the experiment showed significant effects of the place where primes were seen [lab vs. poster$F(1,62)=7.6, p<.01]$ and exemplar type [same vs. different $-F(1,62)=10.9, p<.01]$. The interaction between these factors approached significance $[F(1,62)=2.85, p=$ .096 , reflecting the somewhat greater difference between same and different exemplars for the lab than for the poster faces. No effects involving background color were found.

An items analysis was conducted in order to compare RTs for primed items only, where all 16 items served in all conditions under investigation (same vs. different exemplar; same vs. different background color; poster and lab presentation). This gave a significant effect of background color [mean time to respond to primed items on the black background $=656 \mathrm{msec}$, compared with $711 \mathrm{msec}$ on the gray background; $F(1,15)=40.4, p<.001]$, but, as the subjects analysis had shown that this effect was as great for the unprimed items, we conclude that it arises because of differences in the overall speed of different subject groups. The items analysis also revealed a marginally significant effect of same versus different exemplars $[F(1,15)=$ $4.51, p=.051$ ], but no other effects were significant (all other $p \mathrm{~s}>.1$ ) on the items analysis, which is of relatively low power, as compared with the subjects analysis.

As is shown in Table 2, errors were infrequent, as in other experiments in this series (for example, an error rate of $6 \%$ arises when only 8 of the 32 subjects made a single error in any primed condition). Error rates were uniform across conditions, except that significantly fewer were made when test faces were primed by same pictures in the lab - the condition that also yielded the fastest RTs in this experiment.

Interference in episodic memory. There was no significant difference in the time taken or the accuracy of rejection of poster faces that had appeared in the same (958 msec, $S D=153 \mathrm{msec}, 4.7 \%$ errors) or different (944 msec, $S D=162 \mathrm{msec}, 7.0 \%$ errors) views, as compared with the novel, unprimed faces ( $953 \mathrm{msec}, S D=169 \mathrm{msec}$, $3.5 \%$ errors) (all $p \mathrm{~s}>.1$ ). Hit rates for lab faces were $98.9 \%$ for same and $94.1 \%$ for different faces. No effects of background color were found.

Direct test of episodic memory. Although there was only a small sample of subjects, the results mirror those 
Table 2

Mean Reaction Times (RTs, in Milliseconds) and

Percentage of Errors, With Standard Deviations (SDs),

in the Test Phase in Each Condition of Experiment 4

\begin{tabular}{|c|c|c|c|c|c|c|c|c|}
\hline \multirow[b]{3}{*}{ Prime Type } & \multicolumn{8}{|c|}{ Background Color } \\
\hline & \multicolumn{4}{|c|}{ Same } & \multicolumn{4}{|c|}{ Changed } \\
\hline & RT & $S D$ & $\%$ Errors & $S D$ & RT & $S D$ & $\%$ Errors & $\overline{S D}$ \\
\hline \multicolumn{9}{|l|}{ Poster } \\
\hline Same exemplar & 648 & 124 & 6 & 10 & 722 & 226 & 4 & 9 \\
\hline Different exemplar & 668 & 154 & 6 & 11 & 744 & 199 & 4 & 9 \\
\hline \multicolumn{9}{|l|}{ Lab } \\
\hline Same exemplar & 597 & 104 & 1 & 4 & 680 & 154 & 1 & 4 \\
\hline Different exemplar & 674 & 175 & 6 & 11 & 708 & 167 & 5 & 10 \\
\hline Unprimed & 730 & 173 & 6 & 11 & 788 & 169 & 7 & 13 \\
\hline Unfamiliar & 833 & 194 & 7 & 7 & 966 & 193 & 10 & 6 \\
\hline
\end{tabular}

reported after Experiment 3. The subjects were extremely accurate at recognizing the laboratory faces, whether seen earlier in the same $(97 \%)$ or in the different $(98.5 \%)$ view, and at rejecting the new, unprimed faces (94\%). The similar performance on same and different exemplars of familiar faces replicates Bruce (1982) and probably reflects a ceiling effect. In contrast, the subjects were highly inaccurate at recognizing the poster faces, whether seen earlier in the same $(54.6 \%$ correct) or in the different $(45.2 \%$ correct) view. With this small sample, there is no significant difference between the same and different faces $(p>.1)$, but the difference is in the expected direction, with performance poorer on the different exemplars.

\section{Discussion}

Experiment 4 used a larger sample of subjects, rotated items around the lab and poster, same and different exemplar conditions, and replicated more convincingly the findings of Experiments 1-3. Repetition priming was found for both poster and lab faces, although the priming effect was smaller from the poster faces (this difference was significant on the subjects analysis but not on the lowerpower items analysis). This may reflect the change in context, although temporal factors cannot be ruled out. However, Bruce et al. (1994) found no difference in priming between 10 min and 1 week, and, as Experiments 2 and 4 involved delays of less than a week (and an average of 2 days) between the first sight of the poster and participation in the experiments, we think the effect of delay is unlikely.

For both poster and lab faces, priming was reduced by a change in view, although, in this experiment (with more power than Experiment 3), changed exemplars on posters did still produce a significant priming effect. Though there was a trend in the subjects analysis for an interaction between the priming place (poster/lab) and exemplar type, the combined effects of Experiments 3 and 4 (see Figures 1 and 2) suggest additivity rather than an interaction. (Experiment 3 showed a nonsignificant trend for a greater effect of changing exemplar for the poster, while Experiment 4 showed a nonsignificant trend for a reduced effect of changing exemplar on the poster.)
The effects of contextual location and pictorial exemplar did not extend to an extrinsic pictorial/contextual manipulation of background color. This manipulation had no effect at all on the amount of priming or on the studies of episodic memory included in Experiment 4.

Finally, the tests of episodic memory included in Experiment 4 confirmed the observations obtained in post hoc studies reported after Experiment 3. Exposure to faces on the poster did not produce any interference, as compared with completely novel (unprimed) items, when these faces were required to be rejected in a test of episodic memory for the lab faces. Thus, whatever the source of the gain in speed of familiarity decision that underlies the repetition priming effect, it does not seem to overlap with the kind of increase in familiarity that might impinge on a

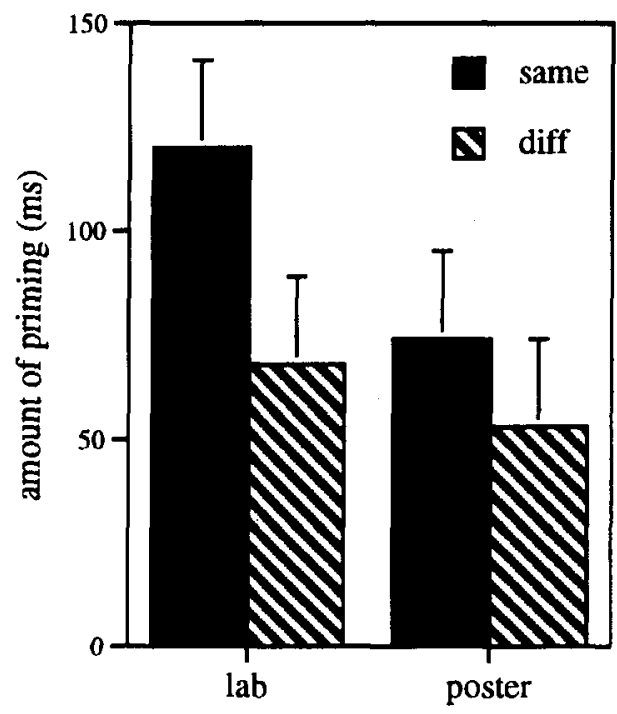

place where prime faces appeared

Figure 2. Amount of priming (mean of unprimed-primed response times, in milliseconds) from same and different exemplars first seen on the poster or in the lab in Experiment 4. Error bars show the within-subjects confidence interval (Loftus \& Masson, 1994). 
recognition memory decision when these same items serve as distractors. However, it is possible that such effects arising from enhanced perceptual fluency to the primed items may be difficult to observe when performance on the target (lab) faces is so accurate (cf. Johnston et al., 1985; Watkins \& Gibson, 1988). It would be interesting to see whether making the episodic memory decision more difficult-perhaps by asking whether the lab faces had earlier been seen in the same or in different photographswould reveal any interference from the increased familiarity of the poster as compared with unprimed items. Perhaps more importantly, if subjects were relying on explicit memory for poster items in the priming experiments, it is difficult to see why this same explicit memory had no apparent influence at all on a test where memories of recently encountered familiar faces were specifically requested in the task demands.

When episodic memory was probed directly in Experiment 4 , we confirmed our earlier observation that memory for the faces on the posters, even in identical exemplars, is extremely weak, as compared with that observed in typical picture recognition performance. ${ }^{4} \mathrm{We}$ cannot, of course, claim that subjects showed no episodic memory for the poster faces - and, indeed, it would be extremely odd if they had, because episodic memory for incidentally learned faces is normally extremely accurate.

\section{GENERAL DISCUSSION}

The series of experiments examined how contextual and pictorial changes affect repetition priming of faces. To recapitulate the main findings of our series of experiments:

1. Repetition priming can be demonstrated for faces shown on advertising posters (Experiments 1-4), although it was reduced in magnitude, as compared with that found for faces encountered in the lab (Experiments 2-4).

2. Repetition priming was found even when the faces were presented quite incidentally and subjects were not obliged to look at them (Experiments 2 and 3).

3. Changing the pictorial exemplar between the prime and test phases affected priming similarly in lab and on the poster (Experiments 3 and 4). Thus, the effect of reduced priming after a change of view is additive with reductions observed after a change in the environmental context within which the faces were primed.

4. Even when different views of faces were initially seen in a different context, measurable priming was found (Experiment 4).

5. A change in the background color on which the faces were presented had no measurable effects on the amount of priming (Experiment 4).

6. Episodic memory for the faces shown on the poster was weak (Experiments 3 and 4). These faces did not give rise to a sense of familiarity that interfered with their rejection as distractors in a test of memory for faces seen in the lab, and they were recognized very much less well than faces seen in the lab when instructions requested subjects to consider both lab and poster faces as old.
These findings have both methodological and theoretical implications. At a methodological level, we have shown pervasive influences of prior presentations of pictures of faces on subsequent familiarity decisions made to them. Although we cannot conclude that priming will transcend changes in all kinds of context (as we discuss below), our observation of substantial priming even from the posters presenting faces incidentally suggests that anyone whose research tests recognition of famous faces should be careful to exclude subjects who may previously have seen any of the faces in any other experiments, however unrelated. Second, the paradigm we have used, of placing items on recruiting advertisements, may prove of interest to those working on the influences of different forms of material for advertising purposes. The influences we have shown of items embedded in incidental material are not novel (although this is the first time such effects have been shown for faces), given some (though not all; cf. Oliphant, 1983) findings in the experimental psychology literature and others in the advertising and marketing literature (see, e.g., Janiszewski, 1988; Nedungadi, 1990). However, this method offers some ecological validity for researchers whose aim is to explore actual influences on perception, attitudes, or behavior of material seen in advertisements.

At a theoretical level, we have demonstrated convincingly that repetition priming of faces does not require the reinstatement of the environmental context specifically associated with the experiment itself. The faces on the posters were seen on different material (on paper), in a different venue, without the experimenter present, and, in some cases (Experiments 2 and 3), with different task demands from those that were encountered in the laboratory, yet priming was observed in these circumstances.

However, some caution should also be exercised over these findings, since, although the contextual manipulation in these experiments encompassed changes found to influence memory for unfamiliar faces, it is not clear to what extent similar variations capture the functional aspects of the context that are important for the identification of or memory for familiar faces. For example, Davies and Milne (1982) reported that changing pictured background context did not reduce the accuracy of recognition memory for pictures of famous faces, although their use of an accuracy measure without associated measures of recognition latency weakens the force of this observation. ${ }^{5}$ On the other hand, Young, Hay, and Ellis (1985) found that volunteers in a diary study of everyday memory frequently reported errors and difficulties in person identification when people were encountered in unexpected places.

For both familiar and unfamiliar face recognition, what may be critical is the interaction between the interpretation of an item and its context. Memon and Bruce (1983) and Beales and Parkin (1984) found that the effects of changing pictured background context were much greater when incidental learning conditions encouraged deep processing of the possible personalities of the depicted faces, an activity that may have enhanced the coding of scenic context. For many familiar acquaintances, the environ- 
mental context in which they are encountered is bound up with their identity ("He's the man from the petshop," or "my neighbor"). However, although environmental context may influence attributions made to relatively unfamiliar faces, the kinds of interpretation given to highly famous faces placed in relative isolation on advertising posters may not be very different from those accessed within the laboratory, and the very mention of experiments may have acted to make these contexts still more similar. In contrast, encounters with famous faces in their more usual circumstances-accompanied by a news item on TV or within the plot of a movie - may involve rather richer semantic contrasts with the laboratory environment, which might reveal stronger effects. What we can say, however, is that repetition priming of familiar faces is not trivially bound to the superficial aspects of context that have been found to influence memory for pictures of faces. Moreover, the robustness of priming across the manipulations used here, and particularly the observation (Experiment 4) of significant priming from different pictures of faces on the posters, confounded our own expectations and those of many colleagues.

Although we would not claim to have demonstrated a perfect dissociation between repetition priming and episodic memory, the episodic memory demonstrated for the poster faces was sufficiently weak to make it unlikely that the observed priming effects arose as a result of explicit memory strategies, particularly given converging evidence from other studies (see, e.g., Ellis et al., 1990). Moreover, at weekly debriefing sessions with Open University students after they had participated in our studies (Experiments 2 and 4) and in informal debriefing of other subjects after studies were completed, large numbers of participants expressed surprise and amusement that the poster faces were an integral part of the experiment. They remembered seeing the posters but had not linked it with events or faces seen later in the priming tasks in the laboratory. Thus, whatever is responsible for the observed repetition priming effects, we doubt that it is a deliberate use of memory of the earlier encounters with the faces.

What is, then, responsible for the observed repetition priming effects? We think that the pattern of results poses some difficulties for both the extreme episodic accounts of priming and the extreme structural accounts. On most interpretations of an episodic account of priming, there should be more of a reduction in priming from a change in context than that which we have observed in these experiments, particularly as the task demands are so different at test from those encountered at priming.

However, an episodic theorist might argue-as we suggested above - that the functional context remains the same on the poster as within the laboratory and thus might demand that we manipulate context more radically. Such a theorist might feel more challenged by an observation in which priming of face recognition occurs despite changes in the deeper functional context surrounding an item. One way to achieve this might be to use faces of people with more than one distinct role (e.g., an actor turned politician), which could be maintained or changed between the prime and the test phases. Such an experiment would be challenging to design (suitable items would be scarce, and careful thought would need to be given to the nature of the test phase). Moreover, any reductions in priming that arose as a result of changes in such interpretative contexts would be relatively easy to accommodate within structural models.

According to Burton et al.'s (1990) interactive activation (structural) account, repetition priming of faces arises as a result of the strengthening of connections between face recognition units (nodes responding to particular individual faces) and person identity nodes (multimodal nodes responding to faces, voices, etc.), the proposed locus of familiarity decisions. Recent simulations (reported in Burton et al., 1998) have used a model that adds a front-end feature analysis based on principal components analysis (cf. Hancock, Burton, \& Bruce, 1996), and this has allowed us to demonstrate that such a model accommodates the effects of a change in the pictured exemplar on the size of the priming effect. Burton (1994) proposes that the same priming mechanism, operating at the level of additional links between feature units and new face recognition units and strengthened when new patterns of elementary facial features are presented, provides an account of how representations of new familiar faces become established. On this account, then, repetition priming taps the same process that underlies the perceptual learning of faces and is the same mechanism by which new faces are learned and representations of familiar faces are modified through encounters with new exemplars. However, the interactive activation account, as currently articulated, would not readily accommodate the effects of changes in environmental context, and, to the extent that priming is, in general, robust from the posters, this supports the model. The slight reduction in priming evident from posters, as compared with laboratory contexts, that was observed in several of our experiments would require modification of the model.

Within a structural account, a possible modification would be to follow the suggestion of Ellis (1992) that the location in which a person is encountered could become integrated-either as an additional source of personspecific information (alongside the person's face, voice, etc.) or as part of the person-specific semantic information - in a way that would produce facilitation of recognition when context is preserved rather than changed. As noted above, for many people known from everyday life, their identities are bound up with the places where they are usually encountered, and our model of person identification should be developed in a way that makes this explicit. Structural models of priming would have little difficulty in accommodating any contextual effects found when deeper levels of interpretation were manipulated through context, since an appeal could be made to the activation and strengthening of different links within the semantic system. Thus if the thought experiment using actor-politicians reduced priming, this would not prove fatal for the structural account, although any failure of such deep contextual ma- 
nipulations would be an even more serious challenge for an episodic account.

The results presented here suggest that the longevity of face priming (cf. Flude, 1993) does not arise because of the maintenance of (at least superficial aspects of) environmental context. Those experiments finding no reduction across delays of 1-4 weeks (see, e.g., Bruce et al., 1994; Flude, 1993) have compared a long delay condition with a baseline condition of 5-10 min delay filled with other experimental tasks. According to a link-strengthening account, there is no reason why the priming effect should reduce across a delay, except to the extent that both primed and unprimed items are encountered in the delay interval, reducing any advantage to primed faces. It is not implausible to suggest that subjects from the populations typically used in such experiments - students who may spend relatively little time watching television or purchasing and reading newspapers - may not, in fact, have very frequent opportunities to sample specific experimental faces across delays of up to a month. Where Flude et al. (1991; Flude, 1993) increased the delay to 3 months, priming was clearly reduced relative to immediate testing and was reduced more for the faces most likely to be encountered in the interval. Although the effects of delay on priming seem to demand a highly contextualized account of repetition priming, we have demonstrated in this paper that repetition priming of faces is affected remarkably little by a change in environmental context. Whether priming would be reduced by a change in interpretative context awaits further research. For the moment, however, we maintain our current hypothesis that priming does reflect the operation of a system mediating the development and updating of the representations used to identify faces.

\section{REFERENCES}

Baddeley, A., \& Woodhead, M. (1982). Depth of processing, context and face recognition. Canadian Journal of Psychology, 36, 148-164.

Bain bridge, J. V., Lewandowsky, S., \& KirSNer, K. (1993). Context effects in repetition priming are sense effects. Memory \& Cognition, 21, 619-626.

Beales, S. A., \& PARKIN, A. J. (1984). Context and face memory: The influence of different processing strategies. Human Learning, 3, 257-264.

Biederman, I., \& CoOPER, E. E. (1991). Priming contour-deleted images: Evidence for intermediate representations in visual object recognition. Cognitive Psychology, 23, 393-419.

BRUCE, V. (1982). Changing faces: Visual and non-visual coding processes in face recognition. British Journal of Psychology, 73, 105-116.

Bruce, V., Burton, M., Carson, D., Hanna, E., \& Mason, O. (1994). Repetition priming of face recognition. In C. Umiltà \& M. Moscovitch (Eds.), Attention and performance $X V$ (pp. 179-201). Cambridge, MA: MIT Press

Bruce, V., \& Hellawell, D. J. (1988). Changing the change-an evaluation of different options for smaller UK coins. Ergonomics, 31, 173191.

Bruce, V., \& Valentine, T. (1985). Identity priming in the recognition of familiar faces. British Journal of Psychology, 76, 363-383.

Brunas-WagstafF, J., Young, A. W., \& Ellis, A. W. (1992). Repetition priming follows spontaneous but not prompted recognition of familiar faces. Quarterly Journal of Experimental Psychology, 44A, 423-454.

Burton, A. M. (1994). Learning new faces in an interactive activation and competition model. Visual Cognition, 1, 313-348

Burton, A. M., Bruce, V., \& Hancock, P. J. B. (1998). From pixels to people: A model of familiar face recognition. Manuscript submitted for publication.

Burton, A. M., Bruce, V., \& Johnston, R. A. (1990). Understanding face recognition with an interactive activation model. British Journal of Psychology, 81, 361-380.

COHEN, J. (1977). Statistical power analysis for the behavioral sciences (rev. ed.). New York: Academic Press.

DAVIES, G. (1988). Faces and places: Laboratory research on context and face recognition. In G. M. Davies \& D. M. Thomson (Eds.), Memory in context: Context in memory (pp. 35-53). London: Wiley.

DAvies, G., \& MiLNE, A. (1982). Recognizing faces in and out of context. Current Psychological Research, 2, 235-246.

Davies, G., \& MiLne, A. (1985). Eyewitness composite production: A function of mental or physical reinstatement of context. Criminal Justice \& Behaviour, 12, 209-220.

Dean, M. P., \& YounG, A. W. (1997). Repetition priming of homographs and novel objects: Evidence for an item-specific locus. British Journal of Psychology, 88, 117-141.

DuCHEK, J. M., \& NeELY, J. H. (1989). A dissociative word-frequency $X$ levels-of-processing interaction in episodic recognition and lexical decision tasks. Memory \& Cognition, 17, 148-162.

Ellis, A. W. (1992). Cognitive mechanisms of face processing. Philosophical Transactions of the Royal Society of London: Series B, 335, 113-119.

Ellis, A. W., YounG, A. W., \& Flude, B. M. (1990). Repetition priming and face recognition: Priming occurs within the system that responds to the identity of the face. Quarterly Journal of Experimental Psychology, 42A, 495-512.

Ellis, A. W., Young, A. W., Flude, B. M., \& HaY, D. C. (1987). Repetition priming of face recognition. Quarterly Journal of Experimental Psychology, 39A, 193-210.

FLUDE, B. M. (1993). Long-term repetition priming of familiar faces. Unpublished doctoral dissertation, University of Lancaster.

Flude, B. M., Young, A. W., \& Ellis, A. W. (1991, July). Long-term perceptual memory for faces. Paper presented to the International Conference on Memory, Lancaster, U.K.

Graf, P., SQUire, L. R., \& Mandler, G. (1984). The information that amnesic patients do not forget. Journal of Experimental Psychology: Learning, Memory \& Cognition, 10, 164-178.

GREENE, R. L. (1986). Word stems as cues in recall and completion tasks. Quarterly Journal of Experimental Psychology, 38A, 663-673.

Hancock, P. J. B., Burton, A. M., \& BruCE, V. (1996). Face processing: Human perception and principal components analysis. Memory \& Cognition, 24, 26-40.

JACOBY, L. L. (1983). Remembering the data: Analysing interactive processes in reading. Journal of Verbal Learning \& Verbal Behavior, 22, 485-508.

JACOBY, L. L., \& Dallas, M. (1981). On the relationship between autobiographical memory and perceptual learning. Journal of Experimental Psychology: General, 110, 306-340.

JANISZEWSKI, C. (1988). Preconscious processing effects: The independence of attitude formation and thought. Journal of Consumer Research, 15, 199-209.

Johnston, W. A., Dark, V. J., \& Jacoby, L. L. (1985). Perceptual fluency and recognition judgements. Journal of Experimental Psychology: Learning, Memory, \& Cognition, 11, 3-11

LofTUS, G. R., \& MASsoN, M. E. J. (1994). Using confidence intervals in within-subject designs. Psychonomic Bulletin \& Review, 1, 476-490.

MAYLOR, E. A. (1998). Retrieving names in old age: Short- and (very) long-term effects of repetition. Memory \& Cognition, 26, 309-319.

Memon, A., \& BRUCE, V. (1983). The effects of encoding strategy and context change on face recognition. Human Learning, 2, 313-326.

NEDUNGadi, P. (1990). Recall and consumer consideration sets: Influencing choice without altering brand evaluations. Journal of Consumer Research, 17, 263-276.

OLIPHANT, G. W. (1983). Repetition and recency effects in word recognition. Australian Journal of Psychology, 35, 393-403.

RoEDIGER, H. L., III, \& BLAXTON, T. A. (1987). Retrieval modes produce 
dissociations in memory for surface information. In D. S. Gorfein \& R. R. Hoffman (Eds.), Memory and cognitive processes: The Ebbinghaus centennial conference (pp. 349-379). Hillsdale, NJ: Erlbaum.

RoEDiger, H. L., III, \& MCDERMOTT, K. B. (1993). Implicit memory in normal human subjects. In F. Boller \& J. Grafman (Eds.), Handbook of neuropsychology (Vol. 8, pp. 63-131). Amsterdam: Elsevier.

Roediger, H, L., III, Weldon, M. S., Stadler, M. A., \& Riegler, G. H. (1992). Direct comparison of word stems and word fragments in implicit and explicit retention tests. Journal of Experimental Psychology: Learning, Memory, \& Cognition, 16, 374-391

Roтн, I., \& BRuCE, V. (1995). Perception and representation: Current issues (2nd ed.). Buckingham, U.K.: Open University Press.

Smith, S. M., GlenberG, A., \& BJoRK, R. A. (1978). Environmental context and human memory. Memory \& Cognition, 6, 342-353,

Thomson, D. M., Robertson, S., \& Vogt, R. (1982). Person recognition: The effect of context. Human Learning, 1, 137-154

Valentine, T., Moore, V., Flude, B. M., Young, A. W., \& Ellis, A. W. (1993). Repetition priming and proper name processing. Do common names and proper names prime each other? Memory, 1, 329-349.

WAGSTAFF, G. F. (1982, July). Context effects on eyewitness reports. Paper presented at the Law and Psychology conference, Swansea, Wales.

WARREN, C., \& MORTON, J. (1982). The effects of priming on picture recognition. British Journal of Psychology, 73, 117-130.

WatKINS, M. J., \& GiBSON, J. M. (1988). On the relation between perceptual priming and recognition memory. Journal of Experimental Psychology: Learning, Memory, \& Cognition, 14, 477-483.

Watkins, M. J., Ho, E., \& Tulving, E. (1976). Context effects in recognition memory for faces. Journal of Verbal Learning \& Verbal Behaviour, 15, 505-517.

Weldon, M. S., Roediger, H. L., III, Beitel, D. A., \& Johnston, T. R. (1995). Perceptual and conceptual processes in implicit and explicit tests with picture fragment and word fragment cues. Journal of Memory \& Language, 34, 268-285.

Winograd, E., \& Rivers-BulKeley, N. T. (1977). Effects of changing context on remembering faces. Journal of Experimental Psychology: Human Learning \& Memory, 3, 397-405.

YounG, A. W. (1994). Conscious and nonconscious recognition of familiar faces. In C. Umiltà \& M. Moscovitch (Eds.), Attention \& performance $X V$ (pp. 153-178). Hillsdale, NJ: Erlbaum.

Young, A. W., HAY, D. C., \& Ellis, A. W. (1985). The faces that launched a thousand slips: Everyday difficulties and errors in recognising people. British Journal of Psychology, 76, 495-524.

\section{NOTES}

1. Roediger and McDermott (1993) restrict the usage of the term repetition priming to situations where both the item and the response are repeated from presentation to test. This departs from usage in the domain of face recognition, where the term repetition priming has been applied to experiments where both the response and the picture vary from study to test phase. Our broader use of the term repetition priming in this paper follows this usage in the face recognition literature.

2. Any possible bias in favor of the poster faces introduced by this screening of subjects through the poster instructions was compensated for in our treatment of results, where only RTs from faces named correctly in the laboratory prime phase were included in the analysis (see the Results section).

3. Indeed, as the same procedure was applied in all experiments, in those in which subjects have not been invited to name faces on the poster, this procedure will tend to bias the design against priming from poster faces that may not have been recognized

4. In our direct test of episodic memory, lab and poster faces were intermixed in the test phase, and it might seem possible that the greater familiarity, through recency, of the lab faces might bias subjects to respond negatively to the poster faces. We think this unlikely. Bruce (1982) reports two experiments in which episodic memory for unfamiliar faces was measured. In the first, all items in the experiment were unfamiliar prior to the experiment. In the second, half of the items were personally familiar to the subjects (faculty members). The accuracy of recognizing previously presented unfamiliar faces was identical in the two studies ( $89 \%$ hits to identical pictorial exemplars), so the additional familiarity through personal knowledge of individual items did not reduce performance with respect to less familiar items in this case.

5. For example, Bruce (1982) found no difference in the accuracy of recognition memory for same and changed views of familiar faces but a significant elevation of recognition latency when views were changed.

\section{APPENDIX A Pilot Work}

Extensive pilot work was conducted in order to collect three matched sets of famous faces (eight in each set) that were equally familiar and for which times to make familiarity decisions did not differ significantly.

Pictures of 46 familiar faces (TV celebrities, pop stars, politicians, and royalty-see Appendix B for examples) were digitized and presented, intermixed with 32 unfamiliar faces, to a group of 9 subjects drawn from the population to be used in the main experiments. These 78 faces were shown for $2 \mathrm{sec}$ each with Superlab. Subjects were asked to perform a familiarity decision for each face as quickly but accurately as they could. RTs and accuracy of response were recorded. After completing the above task, the subjects were presented with the 46 famous faces one at a time and asked to name each one. A second group of 9 subjects was given the same tasks to perform with 30 of the same famous faces shown in different pictorial exemplars and a further 7 famous faces intermixed with $\mathbf{3 0}$ unfamiliar faces.

At the end of this procedure, for each of 53 famous faces $(30$ in two different exemplars), we had collected a mean RT (for 9 subjects) for making a familiarity decision, an accuracy of this decision, the number of times the correct name was given, and the mean response to the two different likenesses for each face.

From this data, we selected exemplars which were correctly named at least six out of nine times. These faces were in turn grouped into three matched sets with approximately equal mean RTs for familiarity decisions.

From these sets, three groups of eight faces were selected. As well as being matched on frequency of naming and mean RT for familiarity decisions, they were also constructed so that there was an approximately similar range of occupational types, ages, and gender balance within each set. The three groups of faces are listed in Appendix B. The mean familiarity latencies for each group of eight faces obtained in this initial pilot work were as follows: for Group 1, $736 \mathrm{msec}(S D=87 \mathrm{msec})$; for Group 2, $731 \mathrm{msec}(S D=99 \mathrm{msec})$; for Group 3, $725 \mathrm{msec}(S D=71 \mathrm{msec})$.

Nine new subjects were then presented with all 24 faces $(8$ from each group), intermixed with six familiar filler items and 28 unfamiliar faces. Their task was to decide whether each face shown in the series of 58 was familiar or unfamiliar, as quickly but as accurately as possible. Each face was shown for 2,000 msec with a 500-msec interstimulus interval (ISI). RTs were recorded. Mean RTs were as follows: for Group 1, $743 \mathrm{msec}(S D=62)$; for Group $2,730 \mathrm{msec}(S D=97)$; for Group 3, $708 \mathrm{msec}(S D=113)$. Although there is some variation in the means obtained in each group, these differences do not approach significance $[F(2,16)=0.91 p=.422]$.

This procedure was repeated 12 months later (towards the end of the series of experiments reported here) to check that the baseline rates of familiarity remained the same. Nine more subjects saw the same series of 58 familiar and unfamiliar faces, and their mean times to recognize the three groups of eight items as familiar were as follows: for Group 1,643 $\mathrm{msec}(S D=58.3)$; for Group 2, $653 \mathrm{msec}(S D=71.5)$; for Group 3, $664 \mathrm{msec}(S D=$ 


\section{APPENDLX A (Continued)}

84.6). There were again no significant differences between these means $[F(2,16)=0.38, p=.69]$.

In the experiments where counterbalancing of items to conditions was not possible, the faces from Group 1 were allocated to the poster condition, those from Group 2 to the primed in lab condition, and those from Group 3 to the unprimed condition. In all experiments, the same set of exemplars of the 24 target faces was used. In experiments where the picture of the celebrity varied between the prime and the test phase, the new picture was used to prime, with the constant set of original pictures being used in the test phase.

Before conducting Experiment 1, we carried out a further pilot priming experiment in which Group 1 and Group 2 were both primed in the lab and Group 3 faces were unprimed. Nine new subjects were tested. In Phase 1 (the prime phase), 16 familiar faces (Groups 1 and 2) were shown for $5 \mathrm{sec}$, and subjects were asked to name them. In Phase 2, the subjects viewed 30 familiar (Groups 1, 2, and 3 plus 6 fillers, 16 primed and 14 unprimed in total) and 28 unfamiliar faces. Each face was shown for $2,000 \mathrm{msec}$, with an ISI of $500 \mathrm{msec}$. A familiarity decision was carried out, and the response and the time taken to make it were recorded. Mean RTs to famous faces were as follows: for Group 1 (primed), $665 \mathrm{msec}(S D=103)$; for Group 2 (primed), $691 \mathrm{msec}(S D=86)$; for Group 3 (unprimed), $813 \mathrm{msec}(S D=$ 128). There was a main effect of priming condition $[F(2,16)=$

\section{APPENDIX A (Continued)}

$13.0, p<.001]$, but there was no significant difference between the primed faces in Group 1 and the primed faces in Group 2 $(t=0.8, p=.5)$.

Therefore, we proceeded with Experiment 1, allocating Group 1 faces to the poster, Group 2 to the set to be primed in the lab, and Group 3 to the unprimed group.

\begin{tabular}{|c|c|c|}
\hline \multicolumn{3}{|c|}{$\begin{array}{c}\text { APPENDIX B } \\
\text { Groups of Faces Selected }\end{array}$} \\
\hline $\begin{array}{l}\text { Primed by Poster } \\
\text { Group } 1 \\
\end{array}$ & $\begin{array}{l}\text { Primed in Lab } \\
\text { Group } 2\end{array}$ & $\begin{array}{l}\text { Unprimed } \\
\text { Group } 3\end{array}$ \\
\hline Prince Charles & David Bellamy & Stephen Fry \\
\hline Norman Lamont & Cliff Richards & Mick Jagger \\
\hline Sean Connery & Bob Geldof & Clive James \\
\hline Paul Daniels & Mikhael Gorbachov & Neil Kinnock \\
\hline Clint Eastwood & John Major & Margaret Thatcher \\
\hline Sarah Ferguson & Queen Elizabeth & Nigel Mansell \\
\hline Douglas Hurd & Sylvester Stallone & David Owen \\
\hline Rod Stewart & Terry Waite & Terry Wogan \\
\hline
\end{tabular}

(Manuscript received July 15, 1996; revision accepted for publication January 25, 1997.) 